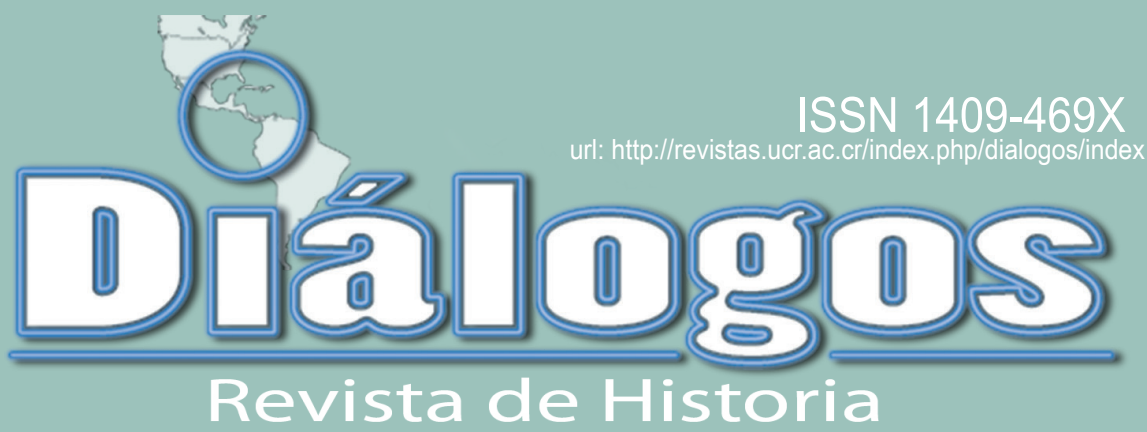

Escuela de Historia. Universidad de Costa Rica Vol. 15 No. 2 Setiembre 2014 - Enero 2015

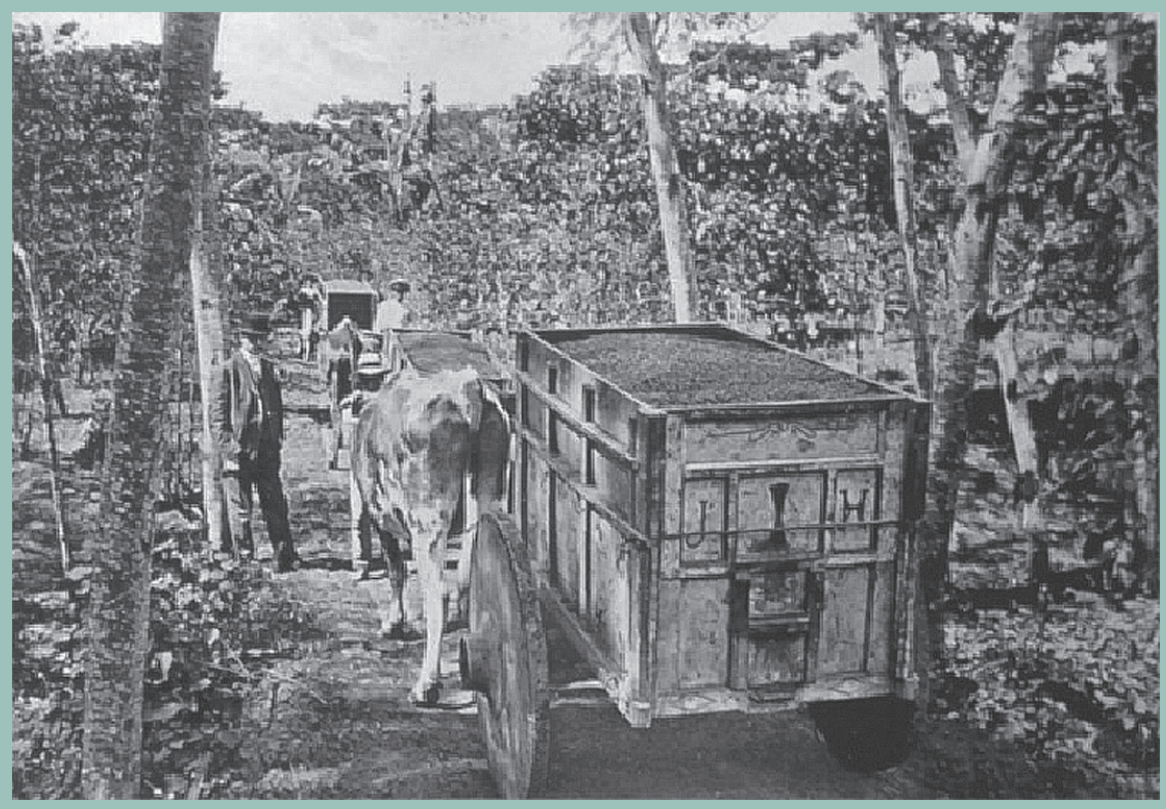

Director de la Revista: Dr. Juan José Marín Hernández juan.marinhernandez@ucr.ac.cr

Editor académico: Dr. David Díaz Arias - david.diaz@ucr.ac.cr Editor técnico: M.Sc. Marcela Quirós G. - marcela.quiros@ucr.ac.cr

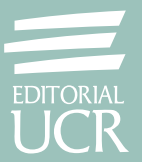




\section{HISTORIA DE}

CENTROAMÉRICA 


\title{
POLÍTICA EXTERIOR E IDENTIDAD NACIONAL. EL CASO DEL ASILO AL GENERAL GERARDO BARRIOS ESPINOZA (1863-1865)
}

\author{
FOREIGN POLICY AND NATIONAL IDENTITY. THE GENERAL BARRIOS'S \\ ASYLUM CASE (1863-1865)
}

Carlos Humberto Cascante Segura

\begin{abstract}
Palabras claves
Historia de la política exterior, construcción de identidad nacional, percepción de Centroamérica, asilo diplomático.

Keywords

Foreign Policy History, national identity building, Central America perception, diplomatic assylum.

Fecha de recepción: 7 de febrero, 2014 - Fecha de aceptación: 1 de junio 2014

\section{Resumen}

A partir de la relación entre los conceptos de construcción de identidad y política exterior, el artículo analiza el caso del asilo diplomático concedido por el gobierno de Costa Rica al expresidente salvadoreño Gerardo Barrios Espinoza. Este acontecimiento permite visualizar cómo el escenario internacional y las acciones que se tomen en ese campo afectan en diferentes perspectivas las relaciones internas de poder dentro de la Costa Rica de mediados del siglo XIX.
\end{abstract}

\begin{abstract}
From the relationship between national identity building and foreign policy, this essay analyzes the case of diplomatic asylum granted by the government of Costa Rica to the former Salvadoran president Gerardo Barrios Espinoza. This event allows to undestandhow the international scenario and the actions made and executed in this ambit affect from different perspectives the domestic power relations within the mid-nineteenth century Costa Rica.
\end{abstract}




\section{CONSIDERACIONES INICIALES}

La relación entre la construcción de identidad y la política exterior (elaboración y puesta en ejecución) constituye un tema abierto para el debate en el campo de la historiografía nacional. El abordaje de esta relación, por ende, requiere de un acercamiento teórico que se ha elaborado, con cierto grado de continuidad, en la literatura de otras latitudes, y con mayor constancia en el ámbito de la disciplina de las Relaciones Internacionales que en la historiografía ${ }^{1}$. En tal sentido este trabajo se propone, por una parte, efectuar un breve recorrido por los conceptos teóricos básicos que se han construido en el estudio de dicha relación. Por otra, a partir de estos esbozos teóricos, analizar el caso del asilo al ex presidente salvadoreño Gerardo Barrios Espinoza, concedido por el gobierno costarricense en los primeros meses de 1865, como un ejemplo de la relación entre la política exterior costarricense y su particular proceso de construcción de la identidad a mediados del siglo XIX.

La reconstrucción de la coyuntura histórica de Barrios Espinoza en Costa Rica será elaborada a partir de los periódicos que se conservan de la época (El Ensayo y la Gaceta Oficial), así como la correspondencia oficial que se intercambió relacionada con dicho trance diplomático. Cabe mencionar que este caso ha sido relatado anteriormente ${ }^{2}$, no obstante, la serie de aristas que se encuentran inmersas en dicho caso no han sido debidamente profundizadas. Desde esta línea de análisis, el texto se encuentra estructurado en cinco apartados. El primero se concentra en plantear un sucinto enfoque teórico de ambos fenómenos, el segundopretende contextualizar las relaciones políticas centroamericanas en la década de 1860, el tercero establece el panorama de la política costarricense de esos años, el cuarto se concentra en las acciones de política exterior desarrolladas por el gobierno y el contenido de los discursos empleados, el quinto se dirige a revisar los efectos de esta crisis diplomática; finalmente, el sexto, se concentra en el abordaje que se brindó en uno de los diarios que se conserva de la época a estos sucesos.

\section{ALGUNOS APUNTES TEÓRICOS. IDENTIDAD Y POLÍTICA EXTERIOR}

El estudio crítico de la relación entre los procesos de construcción de identidad y política exterior se intensificó con el final de la Guerra Fría, cuando un grupo considerable de países enfrentaron el reto de reconstruir su identidad nacional, en razón de los cambios geopolíticos producidos por el descalabro soviético, la disminución de influencia del marxismo en los discursos nacionales y la consolidación de varios procesos de integración regional (la Unión Europea, el más consistente) ${ }^{3}$. Contribuyó, igualmente, a este replanteamiento que en el plano teórico se produjo un 
significativo cuestionamiento a las teorías realistas de las relaciones internacionales, dominantes hasta ese momento, que sobreponen el pragmatismo geopolítico ligado a la omnipresencia del Estado a los componentes psicológicos y axiológicos del comportamiento de las personas y grupos que actúan internacionalmente (Prizel, 1998, pp. 12-37) ${ }^{4}$. A su vez, se nutrió este proceso de la revisión crítica al concepto de nacionalidad en disciplinas como la sociología y la historiografía, que se profundizaron desde la década de 1980, cuando surgió una fecunda discusión académica a partir de textos como los de Benedict Anderson (1991) y Eric Hobsbawm (2002).

Cabe resaltar, que los estudios realizados en este ámbito no realizan una clara conceptualización del término política exterior ${ }^{5}$, sino que este se ha empleado, en términos generales, como las acciones - planificadas o no - que van dirigidas hacia otros actores internacionales. No obstante, han planteado que la relación entre ambos procesos resulta dinámica, compleja y condicionante. Es decir, estos fenómenos se encuentran intercomunicados en diversos aspectos y, consecuentemente, experimentan efectos recíprocos. Desde esta perspectiva, la construcción de la identidad y la política exterior constituyen una relación dialéctica, que puede ser estudiada desde diversas prismas, que pueden identificarse, con fines analíticos, en tres espacios: (a) la política exterior como reflejo de la identidad nacional, (b) la política exterior como instrumento para la construcción de la identidad nacional y (c) la política exterior y la construcción del rol internacional del Estado.

Desde el primer espacio, el cual ha sido identificado continuamente por la literatura especializada, establece que la política exterior constituye un reflejo de la identidad nacional. Por ende, las visiones de la realidad doméstica permean y conducen la forma en que los estados se comportan en lo internacional. En otros términos, los mitos y valores que se construyen en lo interno contribuyen a diseñar los códigos con que se comprende lo internacional, de forma que construcciones identitarias llevan a establecer un rol internacional. En este sentido, la conservación de los grandes intereses y patrones de la política exterior no resulta más que el resultado de la consolidación y conservación de la identidad nacional (Hixson, 2008, pp. 66-68).

La segunda perspectiva conlleva una dirección contraria. Desde esta, la política exterior se conceptualiza como un instrumento dirigido a construir la identidad nacional. Por consiguiente, al desarrollar su actividad internacional, los agentes encargados de tomar decisiones emplean los discursos y resultados de la política exterior para conseguir objetivos domésticos, dentro de los cuales se encuentra la consolidación de una imagen interna, que se configura al contraponer esta con los otros actores de la sociedad internacional. Esto permite la configuración de una jerarquía interna, que se consolida con los discursos y resultados que se alcanzan en el ámbito internacional. Este método, usado tradicionalmente en el ejercicio 
político, tiende a incrementarse cuando la élite política se percibe a sí misma en una situación de debilidad. De forma tal que, la política exterior - discursos y acciones - contribuyen a reafirmar la unidad de grupo, mediante la difusión de una imagen (Prizel, 1998, p. 19).

La tercera línea de análisis pretende estudiar la relación política exterior e identidad nacional en ámbito de la sociedad internacional. En tal sentido, se concentra en determinar la forma en que el discurso y las acciones de la política exterior construyen una imagen del Estado, el cual se reproduce con el propósito de asumir un rol dentro de la sociedad internacional. Esta seriede discursos y conductas permiten construir en los interlocutores una percepción, que termina por dirigir las relaciones entre estos mediante determinados códigos de conducta (Lahneman, 2003). Así, los grupos que formulan la política exterior de un Estado pueden alcanzar grados distintos éxito; o bien, pueden entrar en contradicciones con la construcción doméstica de la imagen. Situaciones que son igualmente sujetas al análisis y evaluación.

En este sentido, la relación planteada permite un acercamiento novedoso a la historia de las relaciones internacionales de Costa Rica, en particular, a la historia de su política exterior. Un enfoque necesario para comprender el desarrollo político costarricense y su actual visión del contexto internacional. Con tal fin, en los próximos apartados se analizará la coyuntura del asilo político brindado al expresidente de El Salvador Gerardo Barrios, durante los últimos meses de 1864 y los primeros de 1865 .

\section{LA INFLUENCIA DE LO REGIONAL EN LO LOCAL}

La Centroamérica de mediados del siglo XIX se caracterizó por intensos conflictos internos y regionales. Si bien, tradicionalmente, se ha señalado que la división en la política centroamericana constituía una lucha entre liberales y conservardores, lo cierto es que, como señala Gudmundson, existían duros problemas intraclase, que se reflejaban en la lucha entre los gobiernos centrales y gobiernos locales (1994, pp. 207-208). Estas disputas constituían, por ende, procesos iniciales de centralización del poder político y de la fundación de los Estados nacionales, que trajeron consigo una considerable cantidad de desplazados políticos. Para muchos de estos personajes, el exilio y el asilo tenían como fin conseguir los apoyos necesarios para nuevas intentonas de retornar al poder. Algunos ejemplos de este comportamiento fueron los casos de Francisco Morazán y Juan Rafael Mora Porras. No resultaba extraño, por ende, que los caudillos triunfantes realizaran intervenciones en los países vecinos para evitar que estos se transformasen, a su vez, en bases para las intentonas de los líderes derrocados (Cascante, 2013). 


\section{Tabla 1}

PRINCIPALES OBJETIVOS ESTRATÉGICOS DE LA POLÍTICA EXTERIOR HACIA

CENTROAMÉRICA DE GUATEMALA, EL SALVADOR Y COSTA RICA (1850-1865)

\begin{tabular}{|c|c|c|}
\hline PAÍS & PRESIDENTE & PRINCIPALES OBJETIVOS ESTRATÉGICOS \\
\hline \multirow{2}{*}{ Guatemala } & \multirow{2}{*}{ Rafael Carrera y Turcios } & $\begin{array}{l}\text { Rodear al gobierno de El Salvador, con cuyas elites económicas } \\
\text { se mantenían conflictos previos, mediante el control del gobierno } \\
\text { de Honduras y la alianza con el gobierno de Nicaragua. }\end{array}$ \\
\hline & & $\begin{array}{l}\text { Evitar el retorno de posibles amenazas al predominio } \\
\text { guatemalteco en el norte de Centroamérica (en especial, de } \\
\text { Gerardo Barrios). }\end{array}$ \\
\hline El Salvador & Gerardo Barrios Espinoza & Controlar al gobierno de Honduras para rodear a Guatemala. \\
\hline Costa Rica & $\begin{array}{c}\text { Francisco María } \\
\text { Montealgre / Jesús Jiménez } \\
\text { Zamora }\end{array}$ & $\begin{array}{l}\text { Mantener una relación lejana del conflicto Centroamericano. } \\
\text { Mantener una relación amistosa con Nicaragua, para que este } \\
\text { país fuese un tapón de la guerra entre los estados del norte de } \\
\text { Centroamérica. }\end{array}$ \\
\hline
\end{tabular}

Nota: elaborado a partir de Cascante (2013).

En este marco, existían una serie de objetivos estratégicos, que implicaban altos grados de intervención en la política interna de los demás países (ver Tabla 1). La serie de objetivos señalados concluyó con un enfrentamiento directo entre la Guatemala y El Salvador, donde intervenían resentimientos coloniales y una animadversión manifiesta entre sus dos caudillos, Carrera y Barrios. El enfrentamiento se saldó con el derrocamiento de los gobiernos liberales de Honduras y El Salvador, quienes fueron controlados por Carrera, lo que trajo consigo la expulsión de Barrios de su país a finales de 1863 (Cascante, 2013, pp. 15-19). Esta consecuencia vendría a complicar el objetivo costarricense de mantenerse alejado del conflicto centroamericano.

\section{"MONTEALEGRISTAS" Y "TINOQUISTAS", EL COMPLICADO CONTEXTO INTERNO}

La década de 1860 tampoco fue especialmente tranquila dentro de la política costarricense. La oligarquía nacional se debatía en una serie de conflictos políticos intraclase, que se incrementó tras la salida de Juan Rafael Mora Porras (1849-1859), 
pues tras el gobierno de casi diez años se consolidaron tres grupos de poder. La facción ligada a la poderosa familia Montealegre, conformada por los miembros más relevantes del comercio, los cafetaleros e intelectuales liberales, dentro de los que se encontraban, además de los hermanos José María y Francisco Montealegre; Aniceto Esquivel Sáenz, Manuel José Carazo, Lorenzo Montúfar y León Fernández Bonilla. Por otra parte, la denominada facción "tinoquista", compuesta por Julián Volio Llorente, Francisco María Iglesias y Saturnino Tinoco; todos vinculados por lazos familiares con el obispo Anselmo Llorente y Lafuente (Ibíd, p. 11). Con el paso de los años, se fue reestructurando una facción "morista", integrada por familiares de Mora Porras, dentro de los cuales se destacaba Manuel Arguello Mora. No obstante, esta no llegó a tener el peso que tenían las anteriores (Fallas, 1999, pp. 253-254).

Fallas Santana ha sostenido que ambos grupos se diferenciaban por sus apreciaciones sobre tolerancia religiosa, la construcción de un ferrocarril al Atlántico, la educación pública y, en especial, por la disputa en el manejo del sistema financiero (ambos grupos se enfrentaban por la apertura de un banco emisor y de crédito). Tal situación económica se apreciaba en los fuertes enfrentamientos en el Congreso y una serie de intrincados juegos de negociación política para integrar los gobiernos durante esta coyuntura; de forma tal que se evitase un conflicto abierto entre ambas fuerzas (Ibíd, 254). La disputa financiera fue finalmente ganada por el grupo montealegrista, el que junto con capital británico fundó el Banco Anglo Costarricense, con lo que tomó el dominio de esa materia en Costa Rica (Villabolos, 1981, pp. 84-101).

La disputa descrita se reactivó con motivo de las elecciones que debían celebrarse en 1862. En este proceso se enfrentarían Julián Volio Llorente, por parte del grupo "tinoquista" y Aniceto Esquivel Sáenz, por el grupo "montealegrista". Para evitar un posible conflicto entre ambos bandos, las cúpulas militares impulsaron una transacción política que llevó al poder a Jesús Jiménez Zamora (Argüello, 1898, 192). Inicialmente, Jiménez Zamora siguió el esquema de repartición de puestos entre las facciones, para lo cual eligió a José Ulloa Solares como secretario de Interior y carteras anexas; Francisco Echeverría como secretario de Hacienda; y Aniceto Esquivel Sáenz, como secretario de Relaciones Exteriores a (Ibíd, p. 192). Repentinamente, y sin que se hayan determinado las razones, Jiménez prefirió establecer una alianza con el "tinoquismo", por lo que poco tiempo después se sustituyó Esquivel Sáenz por Julián Volio Llorente en la cartera de Relaciones Exteriores e Instrucción Pública (Sáenz Carbonell, 1996, p. 293).

Un hecho acaecido pocos días después de esta permuta demuestra como el conflicto fue tomando cada vez más fuerza en la elite política costarricense. Este consistió en la difusión de noticias sobre una serie de contrataciones de agentes filibusteros por parte del gobierno salvadoreño en su enfrentamiento con 
Guatemala. La fuente de la información era el ministro plenipotenciario en Washington, Luis Molina y Bedoya. Por tal motivo, el 7 de julio, el canciller Volio solicitó al Congreso se concedieran al Poder Ejecutivo potestades extraordinarias para enfrentar la amenaza (González Víquez, 1981, pp. 163-164). El Congreso aún se encontraba dominado por los "montealegristas", de forma que, tras la discusión legislativa, se respondió a Volio que los informes resultaban exagerados. En tal sentido, señalaban que:

\begin{abstract}
"La Comisión se promete de vosotros, señores Senadores y Representantes, que no se le pondrá en la necesidad de puntualizar en el dictamen que le ocupa, además de los ya mencionados, los muchos motivos reales o aparentes que la mueven a recomendaros neguéis, como innecesarios en lo que se refiere a lo exterior y peligrosas en lo interior, las facultades extraordinarias que el Supremo Poder Ejecutivo pide al Congreso Nacional le confiera” (Ibíd, p. 276).
\end{abstract}

Volio respondió que solicitaba una copia certificada de la resolución del Congreso para "en su vista tranquilizarse y tranquilizar al público sobre una eventualidad que no hay que temer a que se realice [la amenaza]" (Citado por González Víquez, en Ibíd, p. 165). Esta crisis empeoró un mes después, con la decisión del gobierno de disolver el Congreso, bajo el argumento de incompatibilidad de las funciones parlamentarias con las municipales (Ibíd, p. 166).

Mientras esto ocurría, Carrera había logrado deshacerse de la amenaza de Barrios Espinoza y había tomado El Salvador, como se señaló anteriormente (Cascante, 2013, pp. 29-30). Barrios arribó a Nueva York, donde no consiguió ningún apoyo para realizar una intentona de restauración. Por tal motivo, decidió regresar a Centroamérica y pedir asilo en Costa Rica. Las razones para esta decisión no se encuentran claras del todo, pero con el apoyo de Lorenzo Montúfar y otros exiliados del liberalismo centroamericano consiguió arribar a Costa Rica y solicitar su asilo político (Montúfar, 1898, p. 381). Al llegar a Guatemala, la noticia provocó una airada nota, en la cual se quejaba con anticipación de cualquier tipo de apoyo costarricense a la causa de Barrios y, además, se amenazaba con el rompimiento de relaciones diplomáticas. La amenaza de Carrera también fue seguida por el gobierno de Nicaragua, lo cual inmiscuía directamente al gobierno costarricense en el enfrentamiento centroamericano. La nota de respuesta del gobierno costarricense fue igualmente dura. Se indicaba que la visita de Barrios a Costa Rica no resultaba un acto inamistoso contra Guatemala, además, se establecía que de darse el asilo este sería un acto apegado al Derecho de Gentes (Sáenz Carbonell, 1996, pp. 297-298). 


\section{DECISIONES DIPLOMÁTICAS Y ACUERDOS INTERNOS. LAS DINÁMICAS DEL CONFLICTO INTERNACIONAL EN LAS DISPUTAS DOMÉSTICAS}

Así las cosas, el ex presidente Barrios desembarcó en Costa Rica el 27 de diciembre de 1864 e inmediatamente - como había sido anunciado - presentó su solicitud de asilo (Ibíd, p. 299). ¿Cómo percibió la oligarquía costarricense estos hechos?, ¿cuáles visiones se fomentaron en los meses siguientes a raíz de la llegada de Barrios a Costa Rica? y ¿cómo afectó este contexto a la construcción de la imagen interna e internacional de Costa Rica? Desde el apartado teórico que se realizó al principio de este trabajo, de forma ineludible, la amenaza internacional que se había conformado tendría que causar efectos en la imagen que la élite costarricense tenía de sí misma, en contraposición con el resto de Centroamérica. Igualmente, desde el plano teórico, las motivaciones racionales no son las que necesariamente privan en las decisiones de política exterior. A continuación se intentará abordar estas preguntas con fundamento en el caso concreto al cual va dirigido este artículo.

La crisis más evidente al interior del gobierno se concentraba alrededor de brindar o rechazar el asilo para Barrios. Esta disputa ha sido relatada anteriormente por Oconitrillo (2000) y, luego con algunos detalles adicionales por Rodríguez Vega (2010). En resumen de acuerdo con ambos autores, existían al interior del gobierno dos visiones contrapuestas, la del ex canciller Francisco María Iglesias (destacado miembro del "tinoquismo"), quien se mostraba de acuerdo esta decisión, pues constituía una tradición costarricense proteger a aquellas personas que sufrían el ostracismo (Rodríguez Vega, 2010, pp. 132-133). Por otro lado, el canciller Volio Llorente rechazaba dicho escenario, dado que el otorgamiento de asilo rompería el objetivo de alejarse del conflicto de casi tres años entre Guatemala y El Salvador (Oconitrillo, 2000, p. 13; Cascante, 2013, p. 35).

Más allá de esta disputa, que puede resultar anecdótica, constituyen hechos más importantes las acciones tomadas a partir de ese momento por las autoridades costarricenses. Es así, sumamente significativo que el presidente Jiménez y el canciller Volio convocasen a una comisión de notables para resolver el asunto (Idem). Desde un abordaje puramente teórico, lo internacional parecía ser un detonante de la integración nacional y de la comparación con los países del istmo, sin embargo, no existen registros de quiénes fueron convocados a dicha instancia; a pesar de lo cual tampoco se registran protestas contra la actitud tomada por el gobierno ni de un bando ni de otro. Tampoco se ha logrado encontrar evidencia que demuestre que esa fue la intención con que se convocó este encuentro. La comisión de notables se decantó por aprobar el asilo, que fue otorgado el 5 de enero de 1865, bajo la condición para Barrios de no realizar actos que contravinieran la neutralidad costarricense en el conflicto. No es posible determinar cuáles fueron las causas que pesaron en 
la decisión del presidente y en el grupo de notables. Por una parte, resulta factible que existiesen presiones internas del grupo ligado a Montúfar; o bien, las expresiones guatemaltecas previas a la llegada de Barrios causaron una grave impresión y malestar en algunos miembros relevantes del gobierno, lo que causó la molestia necesaria para sostener una posición que no resultaba la más prudente.

Tal y como lo habían previsto, los demás países centroamericanos rompieron las relaciones diplomáticas con Costa Rica: El Salvador, el 3 de enero; Nicaragua, el 20 de enero; Guatemala, el 28 de enero; y Honduras, el 18 de febrero (Sáenz Carbonell, 1996, pp. 299-300). Por ello, el gobierno costarricense remitió una contundente nota diplomática al resto de gobiernos centroamericanos. La misiva en cuestión, era la expresión de una política exterior en ciernes, dado que establecía el carácter soberano del Estado, más allá de la referencia al caso del asilo político. En este sentido, puede afirmarse que este documento contribuía a consolidar dentro de la oligarquía el "discurso de la diferencia" planteado anteriormente por Acuña (2002). En este caso, la diferencia estaba marcada por dos estados evolutivos antagónicos: "pueblos civilizados" y estado de "barbarie". Costa Rica formaba parte de los primeros y mientras que insinuaban que Centroamérica aún no había logrado separarse del segundo. De tal forma, en la nota del 5 de enero de 1865 que informaba el asilo de Barrios a los gobiernos del istmo se indicaba:

\begin{abstract}
"Si el pueblo y el Gobierno de Costa Rica se creyeran dispensados de obedecer las sagradas leyes de la hospitalidad; si el humanitario principio sentado por el gobierno Frances en el año de 1844 y aceptado por todo el mundo culto, no tuviese eco en este pequeño y generoso; si desatendido de nuestra propia dignidad, olvidásemos los deberes que contrajimos al declarar la neutralidad que Costa Rica asumió en la guerra contra el General Barrios, todavía tendríamos que someternos á las leyes consignadas en nuestro códigos, y mas aun, á los Tratados celebrados, tanto con la República de Guatemala, como con la del Salvador, mas inmediatamente interesadas en este asunto” (sic) (Volio, 1865).
\end{abstract}

Si bien, dicha carta pretendía dejar sentada con claridad la decisión del gobierno, lo cierto es que el documento en cuestión fue también publicado en el periódico oficial. En tal sentido, dado que en el periodo bajo estudio una buena parte de la población no se encontraba alfabetizada ${ }^{6}$, la información suministrada a partir de periódicos se encontraba dirigida a sectores que tenían alguna influencia en los asuntos públicos. Es decir, el contexto internacional y las acciones de internacionales que emprendía el gobierno - al menos en parte - eran empleadas para zanjar temporalmente las disputas internas que experimentaba la oligarquía. 
La segunda acción que tomó el Gobierno consistió en remitir dos notas diplomáticas circulares a las misiones extranjeras acreditadas en Costa Rica. En estos textos se explicaban los argumentos de la actuación costarricense frente a los acontecimientos descritos al pequeño el cuerpo diplomático y consular acreditado en el país (integrado por agentes de los Estados Unidos, Gran Bretaña, España, Italia, Bremen, Chile y Francia). Sin embargo, estas notas; así como las respuestas brindadas por el cónsul de los Estados Unidos y la Gran Bretaña, fueron íntegramente reproducidas por la Gaceta Oficial, de forma que la correspondencia no solo buscaba objetivos externos, sino también cumplía efectos internos. El inmediato, consolidar la gestión del gobierno que acaba de salir de un duro trance interno, como quedó expuesto. Uno menos inmediato y, posiblemente no premeditado, fortalecer la imagen interna mediante la visión que proponían agentes externos.

En el texto de la primera nota, de fecha 20 de enero, seguida de la ruptura de relaciones diplomáticas con Nicaragua, se explicaban las razones jurídicas para brindar el asilo. Además, se realizaba una comparación entre la actitud de los gobiernos centroamericanos y el costarricense en los siguientes términos:

\begin{abstract}
"Entre tanto, la actitud de Costa Rica ha sido y seguirá siendo, al paso que firme, conciliadora y de espectativa. Bien pueden las otras Repúblicas cerrar sus puertos á nuestro comercio y cortar las relaciones políticas con este país. Costa-Rica responderá á esos actos hostiles, manteniendo los suyos abiertos á todos los paises, y no poniendo trabas ni obstáculos al comercio: los intereses de la paz son los intereses del pueblo Costarricense: á ellos debe su existencia y su progreso, y no solamente procurará hacerlos permanentes en su propio territorio, sino que tambien contribuirá á su consolidacion en las otras Repúblicas Centro-americanas"(sic) (Gaceta Oficial, 1865, 1/20, p. 1).
\end{abstract}

En tal sentido, los textos reflejan la pretensión de obtener el aprecio de las potencias de la época, pues se establecían las virtudes de un pueblo apegado a la legalidad y, por tanto, al progreso y la civilización. En otros términos, el gobierno pretendía establecer una imagen internacional, la que se encontraba ligada con la identidad que se venía construyendo dentro de la oligarquía. Como se han señalado en algunos trabajos anteriores (Acuña, 2001, p. XXIII; Cascante, 2010; Gólcher, 1998), este proceso no resultaba novedoso para la época, sino que había sido una la labor que había empezado lentamente a desarrollar los representantes costarricenses en el exterior; no obstante, se conoce poco de cómo se efectuaba esa labor con los representantes internacionales en el país. Desde esta perspectiva, la "emergencia diplomática" permitía a las autoridades costarricenses ligar los actos realizados con el derecho de las naciones civilizadas, en contraposición con la riesgosa 
y hasta antijurídica postura del resto de los países centroamericanos (ANCR, Fondo Congreso, $\mathrm{N}^{\circ}$ 6879).

La siguiente circular, emitida el 17 de febrero, fue una reacción a la ruptura de relaciones diplomáticas con Guatemala y El Salvador, en la cual se reiteraba los argumentos jurídicos empleados en la primera. Esta nota fue publicada, junto con los decretos de ruptura de relaciones diplomáticas emanados de ambos gobiernos (Gaceta Oficial, 1865, 2/18, pp. 1-2). Igualmente, fueron publicados en la Gaceta Oficial las respuestas de las representaciones de Estados Unidos, la Gran Bretaña y Francia. En dichas misivas se brindaba un apoyo a las actuaciones diplomáticas costarricenses, lo que, por un lado, servía para apalancar la decisión que el gobierno había tomado y la justicia de su posición en un momento de crisis. Con ello, el contexto internacional contribuía a fomentar la imagen que la oligarquía estaba construyendo en torno a Costa Rica y su diferencia con en relación con sus vecinos. Sin embargo, la evidencia existente no permite definir en su totalidad el éxito alcanzado con esta estrategia.

\section{"COSTA-RICA" VERSUS “CENTRO-AMÉRICA"}

¿Cómo se vinculaban este acto de política exterior y la coyuntura centroamericana con los procesos de construcción de una identidad dentro las élites gobernantes? En un interesante debate que cuestiona fundamentalmente el inicio del proceso de construcción de la identidad Palmer (1992) y Molina Jiménez (2002) sostuvieron que esta identidad nacional se elaboró más tardíamente, en el último tercio del siglo XIX. Por otra parte, Acuña Ortega (2002) plantea que a lo largo de varias décadas, desde la independencia, dichas facciones habían establecido paulatinamente una diferenciación con el resto de los países centroamericanos, en la que se percibía el carácter etnotípico como un elemento fundamental de comparación. En los útimos años, Díaz Arias (2007) y Soto-Quirós (2012; 2013) llegaron a establecer una síntesis en el debate, que examinaba los procesos pre y post la década de 1870 como un proceso con diferentes etapas.

En clave de política exterior y para la coyuntura específica del otorgamiento de asilo, la particularidad se transformó en una realidad evidente, que podía esta-

blecer acciones concretas y necesarias. Desde este plano, la identidad nacional, la imagen internacional y las acciones de política exterior empezaron a concatenarse, de forma que estas brindaban importantes evidencias para el discurso interno, en una suerte de autoafirmación de este último. Las palabras de Jiménez Zamora y Volio Llorente - citadas en el acápite anterior -, así como la correspondencia diplomática del periodo permiten una comprensión de cómo este discurso contribuía a la conformación de una política soberanista. 
Esta partía de concebir a Costa-Rica como una construcción política distante de Centro-América, lo que se encontraba más allá del caso específico de Barrios. Sin embargo, dicho acontecimiento brindaba el escenario ideal para su expresión y un ejemplo - de acuerdo con el discurso en cuestión - incuestionable de la realidad de dicha percepción. El conflicto diplomático, al mismo tiempo, contribuía a consolidar una posición respecto a las visiones existentes sobre los demás países centroamericanos y, por consiguiente, sobre los proyectos de construcción de la unión política centroamericana.

De acuerdo con Acuña:

"[e]n la década de 1860, la conciencia de su diferencia respecto de los otros países centroamericanos y su voluntad de caminar por su propia vía había avanzado en el seno de las elites de una manera casi irreversible" (2002,p. 213).

Al iniciarse esa década, no obstante, permanecía la idea construir la unión centroamericana. De hecho, esta posibilidad se encuentra latente en los discursos presidenciales de esos años, como aparece en 1861, en el mensaje del presidente José María Montealegre:

Costa-Rica desea sinceramente esta union; quiere dar un paso hácia este vital objeto, uniformando en lo posible los grandes intereses nacionales, y sobre todo la Representacion en el Exterior.

La unidad que fuese el resultado de la conquista, la expoliacion y la violencia, sería atentatoria é insubsistente; ella debe ser la consecuencia necesaria de la conviccion de voluntarias concesiones y de pacíficos esfuerzos. Tiempo es ya de que Centro-América conozca los peligros que la rodean, si sigue presentándose débil y disuelta, y sino aparece ante los otros pueblos fuerte y unida en el interior, cuerda y justa en sus relaciones con los demas Gobiernos" (sic)(Montealgre, 1861).

Adicionalmente, en la memoria de 1861, el entonces secretario de Relaciones Exteriores, Francisco María Iglesias señalaba:

"Un hecho que merece una mención especial, es el que a pesar de las escazas relaciones entre las Repúblicas Centroamericanas, de la poca intimidad de sus Gobiernos, de las diferentes tendencias de que están animados y de la variedad de intereses que por desgracia los mueven, la nacionalidad se conserva latente y que en lo concerniente a integridad territorial y a 
conservación de la independencia proclamada el 15 de setiembre de 1821, se mantienen solidarios.”(ANCR, Fondo Congreso, №5800).

El propio Iglesias propuso poco antes del conflicto centroamericano de 1863 una nueva iniciativa para la unión (Sáenz Carbonell, 1996, p. 280). Con el advenimiento del conflicto, en el discurso político, la visión de Centro-América se transformó de una probabilidad a una opción más lejana. Así, en su discurso de toma de posesión, el presidente Jiménez Zamora fijó la línea costarricense de la siguiente forma:

\begin{abstract}
"Por desgracia las otras de Centro-América se ven hoy empeñadas en una lucha que el Gobierno de Costa-Rica no ha podido evitar, procurando un arreglo pacífico de los asuntos que tienen en desacuerdo a los de Guatemala y San Salvador.- En tal situación, Costa-Rica se conservará neutral; pero siempre dispuesta a emplear su influjo en favor de la paz centro-americana" (Jiménez, 1863).
\end{abstract}

Desde esta perspectiva, dentro de la élite existía para esos años - al menos un debate con respecto a la relación que debía construirse con los demás países centroamericanos. Dentro de las razones que pueden esgrimirse para conservar la propuesta unionista se encontraban la existencia de amenazas como las posibles aventuras filibusteras, la Guerra del Pacífico, la invasión francesa a México y la intención de los Estados Unidos de establecer una colonia de esclavos libertos ${ }^{7}$. Estas situaciones se convertía en un acicate para no desechar por completo una unión que, como señala Ortega, "[n]o la deseaba en ese momento pero tampoco la rechaza definitivamente” (Acuña, 2002, p. 214).

Sin embargo, el conflicto centroamericano y el caso de Barrios cambio la prioridad de las amenazas internacionales, en las que los países del istmo pasaron a ocupar un lugar primordial. En relación con esta situación, y como demostración del temor ya existente hacia la actitud del resto de países centroamericanos, el presidente Jiménez señalaba en su informe al Congreso que:

\footnotetext{
"Provistos los almacenes de guerra con un valioso armamento comprado últimamente en Inglaterra, y convenientemente organizadas las milicias, nos encontramos en posesión de los medios de defensa, que todo pueblo libre e independiente debe procurarse cuando se halla en paz" (Jiménez, 1865).
}

Más adelante, agregaba: 
"Por desgracia, las Repúblicas de Centro-América, exagerando los peligros que contra su existencia pudieran surgir, de la presencia de un asilo político en esta, han creído indispensable para su conservación y tranquilidad, cerrar sus relaciones diplomáticas, comerciales y sociales con la de CostaRica, privándose de esta manera de los medios que la amistad ponía a su alcance para vigilar y contener a la persona que tantas inquietudes les causa, desviando de sus puertos nuestro pequeño comercio y ahondando la escisión que, y a la diversidad de principios y a la oposición de intereses ya la diferente organización política, habían abierto entre pueblos que por su origen y su situación geográfica, están llamados a unirse. Nicaragua, sin embargo, ha dejado abiertas las relaciones oficiales.

El Gobierno se ha limitado a protestar contra la injusticia de semejantes medidas; excusando discutir sus actos de soberanía y rechazando la presión que sobre él se haya pretendido ejercer. Su conducta ha merecido elogios de los Gobiernos y de la prensa imparciales" (Idem).

Una posición, mucho más clara y contundente fue expresada por el canciller Volio, quien en su informe al Congreso realizaba la siguiente consideración:

"No obstante la esperanza en que por muchos años permanecieron, de volver a formar un solo cuerpo de nación, expresada en las leyes fundamentales inmediatamente promulgadas; esperanza que ha dado motivo a que algunos crean, por lo menos latente, natural y tan solo aplazada la antigua unión; es lo cierto que cada una aisló sus intereses, declaró su propósito de no intervenir en los negocios de las otras, y vinieron a tratarse entre sí, como si nunca hubiesen estado ligadas [...]" (ANCR, Fondo Congreso, $\mathrm{N}^{\circ}$ 6068).

El diagnóstico de Volio planteado en su informe al Congreso fue apoyado ampliamente por este, como se puede apreciar en la respuesta oficial que brindó el Senado. En este documento, que en principio hace una referencia a la discusión existente sobre el futuro de la unión con Centroamérica, termina por concluir no solo la extinción de todo tipo de cercanía con las demás repúblicas centroamericanas, de cuyos lazos - agregaba - no existía esperanza de recuperación alguna. A su vez, el progreso costarricense se relacionaba con la separación de caminos entre Centro América y Costa Rica. Así se exponía que:

"Nuestra separación definitiva fue la señal del principio de nuestro progreso.

De esa época para acá datan los monumentos que nos honran, desde entonces 
fue que tuvimos rentas, que tuvimos caminos, que tuvimos educación, en una palabra cuanto hoy valoramos" (Idem).

La confirmación de percepciones de la elite costarricense, o al menos un grupo importante de esta, en contraposición con Centro América y los centroamericanos puede apreciarse en un interesante y agitado intercambio epistolar entre el ministro plenipotenciario en Washington, Luis Molina y Bedoya, y Volio Llorente, efectuado pocos meses después de la salida de Barrios Espinoza de Costa Rica. El ministro, nacido en Guatemala y quien había servido cargos diplomáticos para El Salvador, había concordado con Volio en la necesidad de no conceder el asilo a Barrios (ANCR, Fondo Relaciones Exteriores, Caja $N^{\circ} 43$ ). No obstante, y pese haber ejercido como representante de Costa Rica por un largo periodo de tiempo, se consideraba a sí mismo un recio unionista. De tal forma, con motivo del informe del canciller al Congreso le escribió lo siguiente:

\begin{abstract}
"La principal fuente de divergencia entre nosotros: Ud.es Costarricense, exclusivamente la fuerza del nativismo le hace negar y rechazar la union centroamericana, a excepción del caso de invasión filibustera, creyendo que la suerte de esos Estados esta fijada definitivamente con absoluta independencia y talvez que tiene cada uno, o al menos CR, los elementos de desarrollo necesarios para constituir una nación capaz de bastarse a sí misma y de hacerse respetar. Yo nací, me crié y permanezco Centro Americano [...] (sic)" (ANCR, Fondo Relaciones Exteriores, Caja $N^{\circ}$ 44:10:B)
\end{abstract}

La respuesta de Volio reflejaba el "nativismo" planteado por Molina, además, establecía muy claramente la noción de la visión que se fue imponiendo dentro de la oligarquía en relación con Centro América:

"Yo sé perfectamente que Costa Rica es un país pequeño, desprovisto de toda clase de recursos, sin elementos para hacerse respetar y que su debilidad la expone a mil peligros, decepciones y a veces faltas de consideración; pero por otra parte conozco que la unión con los otros Estados de Centro América no la haría cambiar esta situación, complicaría sus dificultades y aumentaría su debilidad y su miseria, sujetándola además a sufrir las consecuencias del necio orgullo de sus vecinos [...]

[...] Lo mismo que Ud. nací centroamericano; pero solo quiero ser costarricense, y nada deseo tanto como que en el exterior se sepa que esta República nada tiene de común con las que un día formaron la Federación, en buena 
hora tan ilógica y tan imposible que no volverá a pensarse en ella mientras subsistan las condiciones actuales de aquellos pueblos" (ANCR, Fondo Relaciones Exteriores, Libro copiador, $\mathrm{N}^{\circ} 140$, f. 36).

Como puede apreciarse, la visión de diferenciada que planteaba la paz costarricense con el conflicto permanente en el resto de países, que se había ido construyendo en los años anteriores tuvo un cambio de tono. Esta consistía en entrelazar ambos componentes, de forma que las particularidades costarricenses se encontraban dentro de un medio amenazante: Centro América. Por ello, Volio planteaba la necesidad de construir una imagen internacional, para que los países ajenos al istmo pudiesen conocer las diferencias entre Costa Rica y Centroamérica. Igualmente, las consecuencias políticas de la ruptura planteadas por Molina, eran soslayadas por algunos de los personajes más conspicuos de ese periodo. En tal sentido señalaba el Dr. Castro Madriz:

"Yo creo que la suspensión de relaciones que ocurrido el Gobierno de El Salvador, seguramente también el de Nicaragua y remotamente el de Guatemala es más perjudicial a sus respectivos pueblos que los de Costa Rica, y que ésta debe manifestarse fría e indiferente en semejante emergencia" (Castro, 1865).

Desde esta línea, la amenaza a la supervivencia del naciente Estado pasaba de ser un componente ligado a las grandes potencias de la época y a las antiguas metrópolis, para estar vinculado con las actuaciones seguidas por las repúblicas centroamericanas. Inexorablemente, en el imaginario, los futuros de Costa Rica y Centro-América habían sido bifurcados. La excepcionalidad solo podía consolidarse con la existencia de una normalidad odiosa y malsana, compuesta por el resto de Estados centroamericanos. La consecuencia, en términos de política exterior, fue la supresión de la idea de una unión futura, para convertirse en un intento del pasado, infructuoso, que debía ser superado.

\section{LA DIFUSIÓN INTERNA DEL DISCURSO DE POLÍTICA EXTERIOR}

¿Cuán difundido se encontraba el discurso descrito en los acápites anteriores dentro de la sociedad costarricense?; ¿qué matices tomaba el discurso al eliminar las "cortesías" diplomáticas? En la Hemeroteca Nacional se conservan para el caso que se estudia en este artículo La Gaceta Oficial y el semanario El Ensayo ${ }^{8}$. En este último se efectuó una detallada crónica de los sucesos relativos al asilo 
brindado al general Barrios. Estas reflejaban la cercanía que tenían tanto el dueño, Fulgencio Carranza, como el editor, Mauro Aguilar, con las ideas soberanistas expresadas por el gobierno. Si bien con esta evidencia no puede concluirse que el gobierno alcanzó un apoyo interno generalizado a causa de una acción de política exterior; lo cierto es que los sucesos vinculados con Centro-América y la amenaza existente facilitaban la difusión de las visiones identitarias basadas en la excepcionalidad costarricense y la peligrosidad centroamericana, de las cuales las ediciones de El Ensayo son un buen ejemplo. En este sentido, el estudio de las noticias vinculadas a este evento permite apreciar el contenido que era presentado a la población alfabetizada.

La cobertura de El Ensayo inició con la llegada de Barrios Espinoza a San José. Al parecer este hecho produjo sentimientos encontrados en el país. El 11 de enero, el editor del semanario describía la llegada de Barrios de la siguiente forma:

\begin{abstract}
"La semana antepasada llegó á esta ciudad el Sr. General Barrios acompañado a su llegada por una numerosa concurrencia, que con anterioridad se había adelantado algunas leguas á topar al ilustre proscrito. Ya entre nosotros ha sido visitado por toda, ó casi toda la sociedad Josefina que le ha dado no pocas muestras de simpatía y aprecio, queriendo sin duda hacer una formal protesta contra ciertas exigencias de las otras Repúblicas Centro Americanas...” (El Ensayo, 1865, 1/11, p. 1)
\end{abstract}

En ese mismo periódico se publicó posteriormente una carta de respuesta, firmada por "Unos costarricenses" que contradecía estas apreciaciones al indicar que:

\begin{abstract}
"Es sobre manera sensible que el Señor Redactor haya dado cabida en las columnas del "Ensayo" á un artículo que de suyo no tiene una correspondencia real y positiva; cuando fueron muy pocas las personas que se dignaron favorecer al expresado General, en su ingreso á esta ciudad; habiendo sido la mayor parte de ella parientes de Su Señora, y tres ó cuatro emigrados movidos por la identidad que con el conservan en principios políticos.- Mas ahora, si por esto se ha lanzado nuestro articulista á deducir que la sociedad Josefina, abriga fuertes simpatías en favor de Barrios, por cierto que una lógica muy peregrina..." (El Ensayo, s.f.)
\end{abstract}

A esta discusión inicial siguió un apoyo decidido a favor de la postura asumida por el gobierno. En este sentido, completamente libre de óbices diplomáticos, en el mismo número el redactor del semanario efectuó una serie de notas y artículos cortos dirigidos a respaldar la decisión del gobierno y a construir una explicación 
de la situación política que se experimentaba. Desde esta perspectiva, señalaba en referencia a los gobierno Guatemala y El Salvador:

\begin{abstract}
“¿Creerá el partido servil ó conservador dominante hoy en otras secciones de Centro-América que nosotros hemos perdido, ó sacrificado como ellos en las ambiciones o el interés personal el pundonor nacional? - ¿Creerán acaso, que por debilidad dejaremos hollar impunemente nuestra soberanía y nuestro orgullo de pueblo libre? Oh! Se equivocan, si tal creen: el pueblo entero tiene á honor repetir con su Gobierno las nobles y valientes frases con que el $\mathrm{H}$. Ministro Sr. Volio ha sabido revindicar el honor nacional" (sic) (El Ensayo, $1865,1 / 11$, p. 1).
\end{abstract}

Más adelante, en el mismo artículo, las comparaciones para fundamentar la superioridad costarricense fueron arto groseras y despojadas de toda cortapisa. No obstante reflejar solo la opinión del periódico en cuestión, lo cierto es que dichas ideas estaban rondando a la sociedad costarricense desde mediados del siglo XIX.

"En efecto, no puede haber mancomunidad de ideas ni intereses entre dos países, si se quiere antípodas. Guatemala cuando se independizó Centro América era, como la Metrópoli, la más adelantada de los seis Estados. Allí habían más luces y mayores riquezas, Costa Rica entonces casi no existía: tal era el atraso en que se encontraba. Hoy Guatemala ha retrocedido cien años, y se encuentra respecto de Costa Rica en un nivel muy bajo; y más bajo aun respecto de su anterior posición. [...] [...] Los que manejan el estado en Guatemala propenden por el absolutismo, están educados bajo las ideas de privilegios y distinciones sociales, y tienen horror a todo aquello propenda á igualar las clases, y predican por la desigualdad de sangre y castas. En Costa Rica no hay círculo exclusivo que maneje los intereses de la nación, y los que hoy forman gobierno son republicanos de corazón amantes de su país y que profesan las doctrinas más benéficas y humanitarias del siglo” (sic) (El Ensayo, 1865, 1/11, p. 1).

Para los autores de estos extractos, en realidad la situación que se había presentado con el asilo político otorgado y la subsiguiente ruptura no era casual. No resultaba viable explicar el problema desde sus características inmediatas. El conflicto que envolvía a Costa Rica con sus vecinos se urdía en causas más complejas, que incluso podían encontrarse en la constitución de los cuerpos políticos de Costa Rica y los demás países centroamericanos. En este caso, dado que el conflicto se concentraba primordialmente con Guatemala, el cronista se enfocaba 
en establecer las diferencias entre los grupos gobernantes de ese país y Costa Rica. Por consiguiente, mientras Guatemala (y junto con ella Centroamérica) se mostraba inmovilista y atrasada, Costa Rica se identificaba como progresista y moderna. Esta reproducción de diadas permitía plantear con facilidad la visión de excepcionalidad que las diversas facciones de la oligarquía costarricense estaban construyendo, con la ventaja de establecer el entorno regional y el caso particular de Barrios como una evidencia sensible de estas afirmaciones.

En las publicaciones del 9 y 26 de febrero, que se produjeron con posterioridad a la ruptura oficial de relaciones diplomáticas, el editor y sus colaboradores utilizaron un lenguaje más áspero e insultante.

\begin{abstract}
"Un particular puede muy bien romper sus relaciones á la hora que se le antoje sin que nadie pueda quejarse, porque á nadie se perjudica; pero los gobiernos deben actuar de muy distinto modo: su conducta está sugeta á reglas establecidas en los principios del derecho internacional. Estas reglas pues, no están al antojo y al capricho de cada uno, y si se falta a ellas su resultado es una grave responsabilidad de que tendrán que dar cuenta en su día los Gobiernos del Salvador y Nicaragua.
\end{abstract}

En cuanto á Costa Rica si las cosas no pasan del actual estado, lo que debemos esperar de la prudencia y tino de la administración, más bien tendrá que felicitarse por la ruptura de las relaciones con las otras Repúblicas. Nuestras relaciones con los Estados C. Americanos estaban reducidas desde hace mucho tiempo á un pequeño comercio que traia ropa de lana de Guatemala; azúcar, arros, sombreros, petates, rebosos y tabaco del Salvador; sombreros, petates, jáquimas, cacao y ganado de Nicaragua, cosas que se pagaban a dinero constante, porque ninguna de nuestras producciones se consume en aquellos estados. Hoy pues esos productos se manufacturan en el país, porque la necesidad es madre de la industria, ó se traerán de otra parte donde se puedan pagar con nuestro café; de modo que los Estados pierden un mercado regular, y Costa Rica gana unos centenares de miles de pesos"(sic) (El Ensayo, 1865, 2/9, p. 1).

Las expresiones del redactor demuestran que existían en las clases letradas dentro de la sociedad costarricense, más allá del gobierno de turno, claras muestras de confianza en las oportunidades de sobrevivencia del recién creado estado. Estas se sobreponían a las dificultades que podía causar la ruptura con los países del istmo, que fueron consideradas insignificantes. En otros términos, el progreso y la futura 
riqueza se encontraban más allá de Centroamérica y, por el contrario, mantener una relación cercana con las antiguos miembros de la República Federal significaría una rémora o, peor aún, un riesgo para el esperanzador porvenir costarricense.

¿Cuáles fueron las razones esbozadas por los redactores de El Ensayo para justificar ese presente? La respuesta fue establecida en la edición del 26 de febrero, donde se publicó lo siguiente:

\begin{abstract}
"Bien miradas las cosas, Costa-Rica nada pierde con el rompimiento de toda relación. Los lazos que un día unieron a la República Federal de CentroAmérica mas bien eran ficticios que verdaderos lazos fraternales, no existiendo como no ha existido nunca la cacareada identidad de origen, de costumbres, de hábitos ni de leyes. En el pueblo Costarricense domina el elemento blanco descendiente de colonias gallegas, que como es bien sabido se conservaron en la península ibérica libres de toda mezcla con los árabes ó moriscos africanos, mientras que en las otras Repúblicas Centro americanas, por una parte las masas son indias, y por otra parte el elemento blanco desciende de colonias venidas de los reinos meridionales de España que durante siete siglos estuvieron bajo dominación de los moriscos; de ahí la profunda diferencia que se nota en los hábitos y costumbres de ambos pueblos, y de aquí también las revoluciones periódicas en unos, y la paz y el progreso en el otro”( $\mathrm{sic}$ ) (El Ensayo, 1865, 2/26, p. 1).
\end{abstract}

De esta forma el cronista ligaba el presente y el destino de Costa Rica, así como el resto sus vecinos con pasado conformado por la conquista y la colonización española. Esta descripción caracterizaba a la población costarricense como pura y, de seguido, la comparaba con la población del resto de Centroamérica, que se establecía como el producto de las mezclas raciales de árabes y, posteriormente, de población nativa. Es decir, la causa de un conflicto puntual se planteaba como una nueva diada entre pureza y mestizaje, parangón que resultaba muy útil para explicar la situación de riesgo que por su excepcionalidad experimentaba el país a causa de sus vecinos. Por consiguiente, el discurso relacionaba el asilo a Barrios como un ejemplo de un estado civilizado, y la ruptura política de los países centroamericanos como un acto propio de pueblos inferiores. Estos elementos serán claramente retomados y profundizados en las décadas siguientes en el ámbito interno para difundir una identidad nacional en Costa Rica (Palmer, 1992). 


\section{CONSIDERACIONES FINALES}

Sin recibir apoyo del gobierno costarricense para sus intereses de restauración, Barrios abandonó el país en mayo de 1865. Meses después, realizó un intento de golpe en su país, que se saldó con un desastroso resultado. De tal forma, tras la derrota se dirigió a Panamá, pero el navío en que escapó debió atracar en el puerto de Corinto, donde fue detenido por las autoridades nicaragüenses. Con la promesa de que la vida del ex presidente no corría ningún riesgo fue entregado al gobierno salvadoreño. Sin hacer mayor caso al compromiso, Barrios fue sometido a un consejo de guerra y luego fusilado el 29 de agosto de 1865 (Sáenz, 1996, pp. 300-301).

La salida de Barrios permitió que se restablecieran las relaciones diplomáticas con Nicaragua y Honduras (ANCR, Fondo Congreso, $N^{\circ}$ 6086). No fue el caso de Guatemala y El Salvador, que se mantuvieron interrumpidas por algunos años más. Empero, la guerra centroamericana de 1863 y, en especial, el problema del asilo habían consolidado en el discurso identitario de la oligarquía costarricense la idea de que, por su diferencia con el resto de los estados centroamericanos, se encontraba más amenazado por su entorno cercano que por las potencias europeas o los Estados Unidos. Esta percepción de amenaza contribuyó a establecer un rechazo por la idea, así como por los procesos unión centroamericana en los años posteriores a estos acontecimientos, por lo que replanteó nuevos mecanismos de relación con sus vecinos, los cuales deben ser estudiados con mayor detenimiento.

El caso en cuestión también demuestra como los acontecimientos internacionales, en especial las coyunturas problemáticas en el entorno centroamericano que afectaron directamente al país, fueron un acicate del proceso de elaboración del discurso nacional costarricense, que merece ser estudiado con mayor profundidad en otros momentos históricos. En esta línea, parece que en este periodo la política empezaba a estar impregnada de elementos del discurso identitario nacional, pero al mismo tiempo se configuraba como un instrumento de autoafirmación. Desde esta perspectiva, a modo de hipótesis y como objeto de estudio posterior, debe analizarse como la agenda de política exterior costarricense ha contribuido a galvanizar las diferencias políticas existentes entre las distintas facciones dentro del país. Lo que no parece quedar claro, aún, es cuándo y cómo se empezó a perfilar un rol internacional que fue aceptado o modificado por el resto de la sociedad internacional. Componente que también debe estudiarse en investigaciones posteriores. 


\section{CITAS Y NOTAS}

1 Empero en ciertas academias se ha producido una clara preocupación por analizar historiográficamente esta relación. Sobre las dificultades del uso de nuevas metodologías historiográficas para comprender el fenómeno resulta significativo el primer capítulo del texto Walter Hixson (2008).

2 Entre estos esfuerzos de investigación se encuentran los de Obregón Loría (1951), López Vallecillos (1965), González Víquez (1973), Meléndez Chaverri (1978) y Sáenz Carbonell (1996).

3 En este desarrollo fue fundamental el texto Bloom (1990). Por otra parte, sobre los cambios en el estudio de la política exterior pueden verse el texto Beasley, Ryan y Snarr (2002, pp. 321-348).

4 Otro ejemplo de este viraje pueden verse en William Wallace (1991, pp. 65-80), Antony Smith (1992, pp. 55-76) y Lisbeth Aggestam (1999).

$5 \quad$ Una discusión sobre este concepto en Murillo Zamora (2012).

6 De acuerdo con los datos aportados por un estudio realizado por Iván Molina Jiménez (2008), para 1864 solamente un $15,7 \%$ (21,2\% de los varones y 10,4\% de la mujeres) de la población se encontraba alfabetizada.

7 Respecto de las intervenciones europeas en América, el gobierno costarricense mantuvo una clara neutralidad hacia los casos de México y el Perú. Ver en este sentido ANCR, Fondo Congreso $\mathrm{N}^{\circ}$ 6044. Asimismo, en relación con la Guerra del Pacífico y como justificación a la ausencia de los sendos congresos convocados por el Perú para condenar las acciones españolas en la memoria al Congreso de 1866, con suma practicidad el entonces secretario de Relaciones Exteriores Julián Volio Llorente señalaba: "Costa Rica ha tenido que lamentar los conflictos que estas dos repúblicas hermanas y amigas, se han encontrado últimamente, con la España, absteniéndose de tomar parte en una cuestión que, por más que se diga, no afecta inmediatamente sus intereses, ni compromete su seguridad.” ANCR, Fondo Congreso, №6879.

8 Dicho inventario se encuentra en la página electrónica de la Biblioteca Nacional, en dirección electrónica: http://www.sinabi.go.cr/biblioteca\%20digital/periodicos/index.aspx. Igualmente, puede consultarse la obra de Quesada Camacho (1986). 


\section{REFERENCIAS}

\section{a) Fuentes primarias}

\section{Discursos y mensajes presidenciales}

Montealegre, J. (1861), Mensaje del Presidente de la República de Costa Rica al Congreso Constitucional. En página electrónica CODIMEP-CR, en dirección electrónica: https://docs.google. com/viewer?a=v\&pid=sites\&srcid=ZGVmYXVsdGRvbWFpbnxtZW5zYWplcHJlc2lkZW 5jaWFsY3J8Z3g6M2E1NzA0NTJhZjBmYjM5OA..

Jiménez, J. (1865), Mensaje del Presidente de la República de Costa Rica al Congreso Nacional de 1865. En página electrónica CODIMEP-CR, en dirección electrónica: https://docs.google. com/viewer?a=v\&pid=sites\&srcid=ZGVmYXVsdGRvbWFpbnxtZW5zYWplcHJlc2lkZW 5jaWFsY3J8Z3g6NzVmODA3NGZiMWQ2YzYwMg. Recuperado de 5 de enero de 2014.

Jiménez, J. (1863), Programa Administrativo presentado al Congreso de Costa Rica, 8 de mayo de 1863. En página electrónica CODIMEP-CR, en dirección electrónica: https://docs.google. com/viewer?a=v\&pid=sites\&srcid=ZGVmYXVsdGRvbWFpbnxtZW5zYWplcHJlc2lkZW5j aWFsY3J8Z3g6MzcwZGZIN2I5MWQ1YWFkYg. Recuperado de 5 de enero de 2014.

\section{Notas y documentos oficiales}

ANCR, Fondo Congreso $N^{\circ} 6044$.

ANCR, Fondo Congreso, $N^{\circ} 5800$.

ANCR, Fondo Congreso, $N^{\circ} 6068$.

ANCR, Fondo Congreso, $N^{\circ} 6879$.

ANCR, Fondo Relaciones Exteriores, Caja N 43. Carta de Luis Molina al canciller Julián Volio Llorente, 19 de diciembre de 1864.

ANCR, Fondo Relaciones Exteriores, Caja N 44:10:B. Carta de Luis Molina al canciller Julián Volio Llorente, 14 de julio de 1865. 
ANCR, Fondo Relaciones Exteriores, Libro copiador, N 140, f. 36. Carta de Julián Volio Llorente a Luis Molina y Bedoya, 10 de agosto de 1865.

Volio, J. (1865). Nota del canciller Volio Llorente a los gobiernos de Guatemala, El Salvador, Honduras y Nicaragua, 5 de enero de 1865. Extracto en El Ensayo, 11 de enero de 1865. En página electrónica de la Biblioteca Nacional de Costa Rica, dirección electrónica:http:// www.sinabi.go.cr/Biblioteca\%20Digital/Periodicos/El\%20ensayo\%201/E1\%20ensayo\%20 1865/dt-El\%20Ensayo_s.f..pdf. Revisado 19 de diciembre de 2012.

\section{Artículos de periódico}

El Ensayo, 11 de enero de 1865. En página electrónica de la Biblioteca Nacional de Costa Rica, en dirección electrónica:http://www.sinabi.go.cr/Biblioteca\%20Digital/Periodicos/El\%20 ensayo\%201/El\%20ensayo\%201865/ak-El\%20Ensayo_11\%20ene_1865.pdf. Recuperado 19 de diciembre de 2012.

El Ensayo, 26 de febrero de 1865. En página electrónica de la Biblioteca Nacional de Costa Rica, dirección electrónica: http://www.sinabi.go.cr/Biblioteca\%20Digital/Periodicos/El\%20 ensayo\%201/El\%20ensayo\%201865/bt-El\%20Ensayo_23\%20feb_1865.pdf. Recuperado 22 de diciembre de 2012.

El Ensayo, 9 de febrero de 1865. En página electrónica de la Biblioteca Nacional de Costa Rica, dirección electrónica:http://www.sinabi.go.cr/Biblioteca\%20Digital/Periodicos/El\%20 ensayo\%201/El\%20ensayo\%201865/bh-El\%20Ensayo_9\%20feb_1865.pdf. Recuperado 22 de diciembre de 2012.

El Ensayo, fragmento sin identificación de fecha. En página electrónica de la Biblioteca Nacional de Cos-ta Rica, dirección electrónica: http://www.sinabi.go.cr/Biblioteca\%20Digital/Periodicos/El\%20ensayo\%201/El\%20ensayo\%201865/dt-El\%20Ensayo_s.f..pdf. Recuperado 19 de diciembre de 2012.

Gaceta Oficial de la República de Costa Rica, 18 de febrero de 1865. En página electrónica de la Bibliote-ca Nacional de Costa Rica, dirección electrónica: http://sinabi.go.cr/biblioteca\%20 digital/periodicos/la\%20gaceta/gaceta\%20oficinal\%201865/be-La\%20Gaceta_18\%20 feb_1865.pdf. Recuperado 26 de noviembre de 2013.

Gaceta Oficial de la República de Costa Rica, 20 de enero de 1865. En página electrónica de la Biblioteca Nacional de Costa Rica, dirección electrónica: http://sinabi.go.cr/biblioteca\%20 
digital/periodicos/la\%20gaceta/gaceta\%20oficinal\%201865/ae-La\%20Gaceta_24\%20 ene_1865.pdf. Recuperado 26 de noviembre de 2013.

\section{b) Fuentes secundarias}

Acuña, V. (2002). La invención de la diferencia costarricense 1810-1870. Revista de Historia de la Universidad Nacional - CIHAC de la Universidad de Costa Rica, 45, 191-228.

Acuña, V. (2001). Felipe Molina y la invención de la diferencia costarricense. En Molina Bedoya, F. Bosquejo de la República de Costa Rica. Costa Rica: Museo Histórico Cultural Juan Santamaría.

Aggestam, L. (1999). Role Conceptions and the Politics of Identity in Foreign Policy. ARENA Centre for European Studies.

Anderson, B. (1991). Comunidades imaginadas. Reflexiones sobre el origen y la difusión del nacionalismo. México: Fondo de Cultura Económica.

Argüello, M. (1898). Páginas de Historia. San José: Imprenta El Fígaro.

Beasley, R. y Snarr, M. (2002). Domestic and International Influences in Foreign Policy. En Beasly, Ryan y otros (eds). Foreign Policy in Comparative Perspective. Domestic and International Influences on State Behavior. (pp. 321-348). Washington D. C.: CQ Press.

Bertrand, M. (2005). Las élites sociales de Guatemala en vísperas de la independencia: estructuras et dinamismos internos. En Álvarez, C. y Sanchez, G. (eds). Visiones y revisiones de la independencia americana, México, Centroamérica y Haití. (37-59). Salamanca: Ediciones Universidad Salamanca.

Bloom, W. (1990). Personal Identity, National Identity and Inter-national Relations. Londres: Cambridge University Press.

Cascante, C. (2010). La elaboración de una imagen y diplomacia incipiente. El primer litigio internacional de Costa Rica (1860-1863). Boletín AFEHC, 46. Recuperado en http://afehc-historiacentroamericana.org/index.php?action=fi_aff\&id=2509

Cascante, C. (2013). Julián Volio Llorente: el Canciller. San José: Ministerio de Relaciones Exteriores - Instituto Manuel María Peralta. 
Díaz, D. (2007), La fiesta de la independencia en Costa Rica, 1821-1921. San José: Editorial de la Universidad de Costa Rica.

Fallas, C. (1999), El Estado nacional: institucionalización de la autoridad y centralización del poder 1849-1870. En Botey, A. (compiladora), Costa Rica: estado, economía, sociedad y cultura. Desde las sociedades autóctonas hasta 1914. (pp. 253-254). San José: Editorial Universidad de Costa Rica.

Gólcher, E. (1998). Imperios y ferias mundiales: la época liberal. Anuario de Estudios Centroamericanos, 24 (2), pp. 75-94.

González, C. (1981). El sufragio en Costa Rica ante la historia y la legislación. San José: Editorial Costa Rica.

González, C. (1973). Obras históricas. San José: Publicaciones de la Universidad de Costa Rica.

Gudmunsud, L. (1994). Sociedad y política (1840-1871). En Historia General de Centroamérica, Tomo III. San José: Flacso.

Hixson, W. (2008). The Myth of American Diplomacy: National Identity and U.S. Foreign Policy. New Haven: Yale University Press.

Hobsbawn, E. y Ranger, T. (eds). La invensión de la tradición. Barcelona: Editorial Crítica.

Lahneman, W. (2003). Changing Power Cycles and Foreign Policy Role-Power Realignments: Asia, Europe, and North America. International Political Science Review, 24 (1), pp. 97-111.

Lindo, H. (1995). Los límites del poder en la era de Barrios. En Piel, J. y Taracena, A. (compiladores). Identidades nacionales y Estado moderno en Centroamérica. (pp. 87-97). San José: FLACSO, Editorial de la Universidad de Costa Rica.

López, C. (2007). Compadrazgos, negocios y política: las redes sociales de Gerardo Barrios (18601863). Boletín AFEHC, 30. Recuperado en: http://afehc-historia-centroamericana.org/index. php?action=fi_aff\&id=1550

López, I. (1965). Gerardo Barrios y su tiempo. San Salvador: Ministerio de Educación Pública.

Meléndez, C. (1978). Documentos fundamentales del siglo XIX. San José: Editorial Costa Rica. 
Meléndez, C (1968). Dr. José María Montealegre. San José: Academia de Geografía e Historia de Costa Rica.

Molina, I. (2002). La comunidad política en la Costa Rica del siglo XIX: crítica al artículo de Víctor Hugo Acuña. Revista Bibliográfica de Geografía y Ciencias Sociales de la Universidad de Barcelona, 7 (367). En dirección electrónica: http://www.ub.edu/geocrit/b3w-367. htm. Revisado $1^{\circ}$ de mayo de 2014.

Molina, I. (2008). Educación y sociedad en Costa Rica: de 1821 al presente (una historia no autorizada). Diálogos Revista Electrónica de Historia, 8 (2), pp. 148-356.

Murillo, C. (2012). Política exterior, hegemonía y estados pequeños. El caso de los países centroamericanos y bálticos. Guadalajara: Universidad de Guadalajara.

Obregón, R. (1951), Conflictos militares y políticos de Costa Rica, San José: Imprenta La Nación.

Oconitrillo, E. (2000). Los grandes perdedores: semblanza de dieciocho políticos costarricenses. San José: Editorial Costa Rica.

Palmer, S. (1992). Sociedad anónima y cultura oficial: inventando la nación en Costa Rica, 18481900. En Molina Jiménez, I. y Palmer, S. (eds). Héroes al gusto y libros de moda: sociedad y cambio cultural en Costa Rica (1750-1900). (pp. 169-205). San José: Editorial Porvenir y Plumsock Mesoamerican Studies.

Prizel, I. (1998). National identity and Foreign Policy. Nationalism and Leadership in Poland, Russia, and Ukraine. Edimburgo: Cambridge University Press.

Quesada, J. (1986). Periódicos en Costa Rica (1833-1986). San José: Centro de Investigaciones Históricas de la Universidad de Costa Rica.

Rodríguez, E. (2010). Biografía de Costa Rica. 4ta Ed. San José: Editorial Costa Rica.

Sáenz, J. (1996). Historia Diplomática de Costa Rica (1821-1910). San José, [Editorial Juricentro], 1996.

Sáenz, J. La primera misión diplomática de Costa Rica en Colombia, San José, [Instituto del Servicio Exterior Manuel María de Peralta], 2009. 
Smith, A. "National Identity and the Idea of European Unity". International Affairs (Royal Institute of International Affairs 1944-), Vol. 68, No. 1 (enero, 1992), pp. 55-76.

Soto, R. (2012). La difusión del etnotipo costarricense: los Apuntamientos de J. B. Calvo, del texto educativo a la propaganda internacional. Boletín AFEHC, 54. Recuperado en: http://afehchistoria-centroamericana.org/index.php?action=fi_aff\&id=3168

Soto, R. (2013). Whiteness studies y relatos de viajeros: los costarricenses en las miradas anglosajonas (1844-1868). Boletín AFEHC, 57. Recuperado en: http://afehc-historia-centroamericana.org/index.php?action=fi_aff\&id=3592.

Villalobos, B. (1981). Bancos emisores y banco hipotecarios en Costa Rica 1850-1910, San José: Editorial Costa Rica.

Wallace, W. (1991). Foreign Policy and National Identity in the United Kingdom. International Affairs (Royal Institute of International Affairs 1944-). 67 (1), pp. 65-80.

Woodward, R. (2002). Rafael Carrera y la creación de la República de Guatemala 1821-1871. Vermont: Plumsock Mesoamerican Studies.

\section{ACERCA DEL AUTOR}

Carlos Humberto Cascante Segura: Universidad de Costa Rica / Universidad Nacional Costa Rica. Licenciado en Derecho por la Universidad de Costa Rica. Máster en Diplomacia por la Universidad de Costa Rica. Máster del Programa Centroamericano en Historia de la Universidad de Costa Rica. Profesor de la Escuela de Relaciones Internacionales de la Universidad Nacional. Profesor del Programa de Maestría en Diplomacia de la Universidad de Costa Rica. 